\title{
IFN $\gamma R 1$ Deficiency Presenting with Visceral Leishmaniasis and Mycobacterium Avium infections mimicking HLH
}

Muhammad Khalid ${ }^{1}$, Sonia Lemos ${ }^{2}$, Katherine Myint-Hpu ${ }^{1}$, Debbie Draper ${ }^{1}$, Jennifer Stoddard $^{3}$, Julie Niemela ${ }^{3}$, Stefania Pittaluga ${ }^{4}$, Sergio Rosenzweig ${ }^{3}$, Ottavia Delmonte ${ }^{3}$, and Luigi D. Notarangelo ${ }^{1}$

${ }^{1}$ National Institute of Allergy and Infectious Diseases

${ }^{2}$ Centro Hospitalar e Universitario de Coimbra EPE

${ }^{3}$ National Institutes of Health

${ }^{4}$ National Cancer Institute

July 12, 2021

\section{Hosted file}

Manuscript, Compound Heterozygous IFNGR-1 Deficiency_PAI_revised.docx available https://authorea.com/users/425145/articles/530019-ifn\%CE\%B3r1-deficiency-presenting-

with-visceral-leishmaniasis-and-mycobacterium-avium-infections-mimicking-hlh 

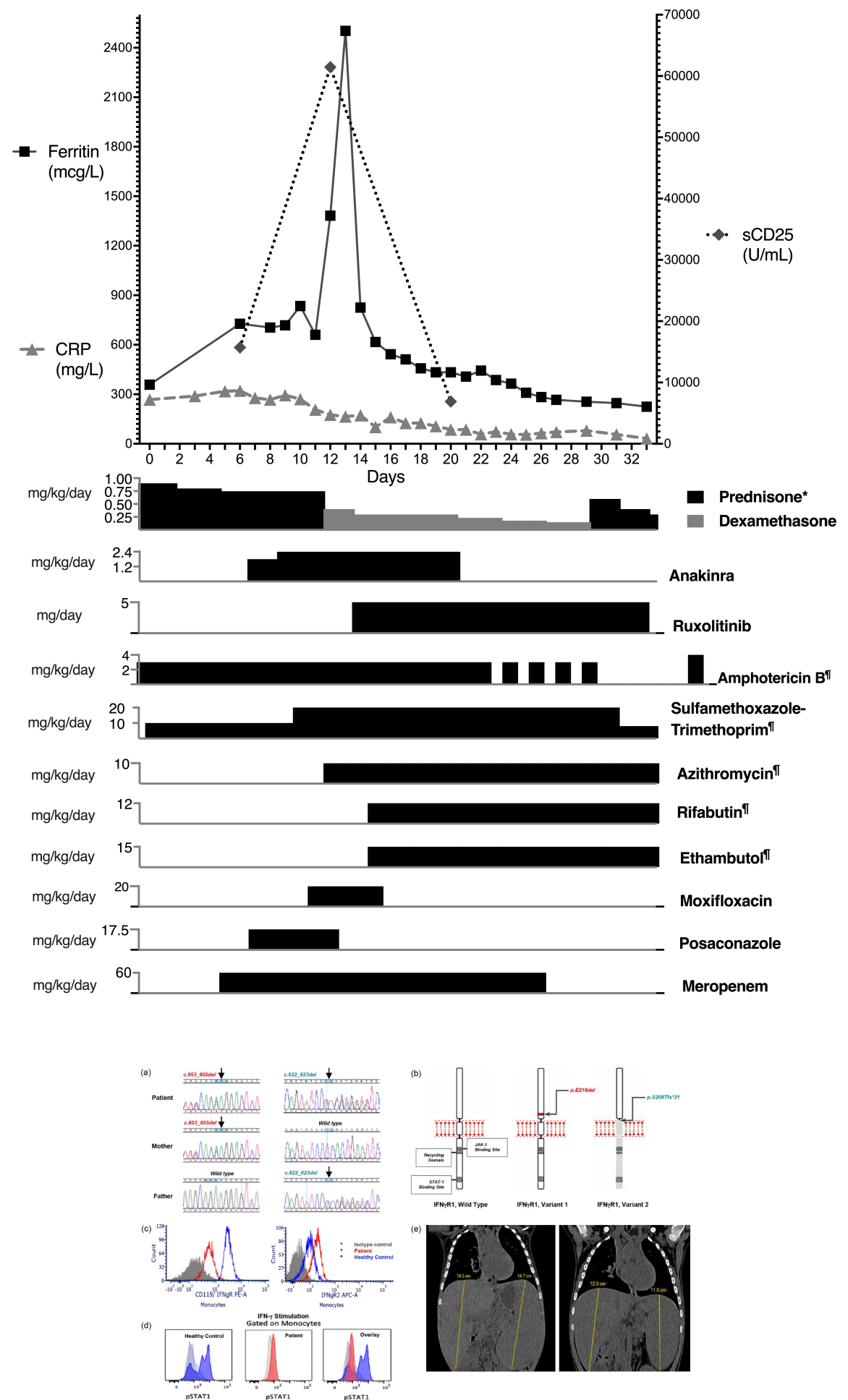

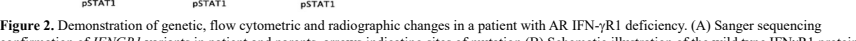
confirmation of IFNGR/ variants in patient and parents, arrows indicating sites of m Flow cytometric analysis in patient compared with healthy control, showing significantly reduced IFNyRI expression and normal IFNYR2 expression (D) Flow cytometric analysis in patient compared with healthy
control, showing absent STAT-1 phosphorylation in response to IFN- $\gamma$ stimulation when gated on monocytes (E) Computed tomography images comparing hepatosplenomegaly at the peak of illness and at time of recovery. 